\title{
Osteoporosis Associated with Chronic Obstructive Pulmonary Disease
}

\author{
Ryo Okazaki, Reiko Watanabe, Daisuke Inoue \\ Third Department of Medicine, Teikyo University Chiba Medical Center, Japan
}

\author{
Corresponding author \\ Ryo Okazaki \\ Third Department of Medicine, Teikyo \\ University Chiba Medical Center, 3426-3 \\ Anesaki Ichihara, Chiba 299-0111, Japan \\ Tel: +81-436-62-1211, Fax: +81-436-7340, \\ E-mail: rokazaki@med.teikyo-u.ac.jp
}

Received: June 2, 2016

Accepted: July 2, 2016

No potential conflict of interest relevant to this article was reported
Recent epidemiological studies have revealed that osteoporosis is closely associated with common chronic diseases including diabetes, hypertension, chronic kidney disorders, and chronic obstructive pulmonary disease (COPD). COPD is a chronic inflammatory airway disease but now well known to be associated with various systemic comorbidities including osteoporosis. Osteoporosis and osteoporotic fractures are extremely common in COPD patients, which have significant impacts on their quality of life (QOL), activities of daily life (ADL), respiratory function, and possibly their prognosis. COPD-associated osteoporosis is however extremely under-recognized, hence undertreated. Recent studies have suggested that both decreased bone mineral density (BMD) and impaired bone quality compromise bone strength causing fractures in COPD. In COPD patients, various general clinical risk factors for osteoporosis are present including smoking, older age, low body weight, and physical inactivity. In addition, disease-related risk factors such as decreased pulmonary function, inflammation, glucocorticoid use and vitamin $D$ deficiency/insufficiency have been linked to the development of osteoporosis in COPD. Increased awareness of osteoporosis in COPD, especially that of high prevalence of vertebral fractures is called upon among general physicians as well as pulmonologists. Routine screening for osteoporosis and risk assessment of fractures will enable physicians to diagnose COPD patients with comorbid osteoporosis at an early stage. Timely prevention of developing osteoporosis together with appropriate treatment of established osteoporosis may improve QOL and ADL of the COPD patients, preserve their lung function and eventually result in better prognosis in these patients.

Key Words: Bone mineral density, Fractures bone, Osteoporosis, Pulmonary disease chronic obstructive, Smoking

\section{INTRODUCTION}

Chronic obstructive pulmonary disease (COPD) is a disease characterized by persistent and progressive airflow limitation associated with a chronic inflammation in the airways and the lung against noxious particles or gases, especially those from inhaled cigarette smoke.[1] COPD is now recognized as a systemic disease with various comorbidities including lung cancer, atherosclerosis, sarcopenia, osteoporosis, diabetes and anxiety/depression. Management of those comorbidities is clinically important as they are associated with hospitalization, mortality and diminished quality of life (QOL) in patients with COPD.[2-4] Osteoporosis is one of the major comorbidities of COPD. Although pathophysiological link between COPD and osteoporosis remains to be established, recent epidemiological studies [5-10]
Mineral Research

This is an Open Access article distributed under the terms of the Creative Commons Attribution Non-Commercial License (http://creativecommons.org/licenses/by-nc/4.0/) which permits unrestricted non-commercial use, distribution, and reproduction in any medium, provided the original work is properly cited.

\section{KSBMR}


including ours [10] from Japan have clearly indicated that osteoporosis is very common in COPD patients. On the other hand, a retrospective chart review of 234 newly-diagnosed male osteoporotics in an US bone clinic identified COPD as the leading cause of secondary osteoporosis, more frequent than glucocorticoid use or hypogonadism.[11] Moreover, osteoporosis-associated fractures may further deteriorate pulmonary function and thereby impair activities of daily life (ADL) of COPD patients. Thus, the two diseases will form a vicious cycle that causes significant burdens on the patients. Osteoporosis in COPD patients is however extremely undertreated. $[5,10,12,13]$ In this review, we will summarize and discuss clinical links and a mutual relationship between COPD and osteoporosis.

\section{CLINICAL LINKS BETWEEN COPD AND OSTEOPOROSIS}

\section{Osteoporosis in COPD}

Osteoporosis is a skeletal disorder characterized by compromised bone strength predisposing a person to an increased risk of fracture. The most important outcome is fracture, and fracture risk depends on bone strength that is determined by bone mineral density (BMD) and bone quality.[14] Because clinical assessment of "bone quality" has not been well developed, diagnosis of osteoporosis has been mainly dependent on BMD. Thus, caution would be needed in the interpretation of previous studies reporting prevalence of "osteoporosis" in COPD as most of them referred to low BMD as osteoporosis while some reports only analyzed fracture prevalence.

\section{Low BMD in COPD}

According to a previous systematic review [5] analyzing a total of 775 COPD patients from 13 studies,[15-27] the prevalence of osteoporosis defined by low BMD was $35.1 \%$ on the average, ranging from $8.7 \%$ to $69 \%$. Three highest numbers were from severe patients awaiting lung transplantation (69\% [19] and 59\% [23]) or hospitalized patients due to acute exacerbation (60\% [16]), whereas the study that reported the lowest number (8.7\% [27]) used calcaneal ultrasonography instead of dual energy $\mathrm{X}$-ray absorptiometry (DXA) for BMD evaluation. More recent studies recruiting stable outpatients demonstrated that prevalence of low BMD (T score $\leq-2.5$ ) was from $18 \%$ to $42 \% .[8,10,28-31]$
The absolute prevalence is however difficult to interpret because BMD is affected by various characteristics of the subjects. The National Health and Nutrition Examination Survey (NHANES) in US demonstrated a $16.9 \%$ prevalence of osteoporosis defined by low BMD in 995 COPD subjects compared to $8.9 \%$ in 14,828 non-COPD subjects, indicating COPD increased the risk of osteoporosis (low BMD) by 1.9-fold.[30] Other cross-sectional studies comparing COPD patients with controls as well as population-based cohort studies have estimated the COPD-associated risk of osteoporosis at approximately $1.5-2$ fold. $[22,26,32,33]$

\section{Prevalent vertebral fractures (VFx) in COPD}

In general, approximately two thirds of VFx are asymptomatic and only a small portion of fractures is recognized as clinical fractures with symptoms. It is thus critically important to assess prevalent morphometric fractures by spinal X-rays. Prevalence of VFx in COPD patients has been reported to be $24 \%$ to $79 \% .[6,8,10,12,25,34-37]$ Again, the values widely vary, depending on the characteristics of study subjects such as age, sex and COPD severity. Some studies included controls for comparison. One study [35] reported that the odds ratio (OR) of having at least one severe VFx in COPD patients was 3.75 compared with ageand sex-matched controls. Another study [6] demonstrated that the prevalence of VFx was $72 \%$ higher in 465 COPD subjects than in 462 controls.

Interestingly, in the latter study, [6] COPD patients appeared to have more VFx in the thoracic than lumbar spine, although both COPD and control subjects had fractures most frequently in the mid-thoracic region (Th7-8) and the thoracic-lumbar junction (Th12-L1). Others [34] reported similar results; $49 \%$ of the subjects had at least one thoracic fracture whereas $16.5 \%$ had at least one lumbar fracture. Another study of 255 COPD outpatients [8] reported 139 thoracic and 33 lumbar VFx. One could only speculate that thoracic vertebrae may preferentially be affected by aberrant physical/mechanical interaction between the lungs and the thoracic cage in the context of thoracic deformities, altered lung compliance, frequent coughing and respiratory muscle wasting as well as biochemical interaction through unknown soluble factors in the local milieu. Predominance of thoracic fractures is still a matter of controversy and requires further investigation. 


\section{Clinical fractures in COPD}

In a large observational cohort study called Global Longitudinal Study of Osteoporosis Women (GLOW),[38] 6.2\% of 52,960 subjects sustained an incident clinical fracture over two years. COPD was among the comorbidities associated with significantly increased fracture incidence (ageadjusted hazard ratio $[\mathrm{HR}] 1.5 ; 95 \%$ confidence interval $[\mathrm{Cl}]$ 1.3-1.7), but information about the fracture site was not provided. A large case-control study (108,754 cases) [39] using UK general practice research database reported that crude OR $(95 \% \mathrm{Cl})$ for osteoporotic fractures was 1.61 (1.521.71) in COPD/asthma patients compared with controls. They also reported significantly increased incidence of hip and clinical VFx in COPD. A more recent cohort study in UK estimated fracture risk in 3,142,673 primary care patients with various comorbid medical conditions and reported that adjusted $\mathrm{HR}(95 \% \mathrm{Cl})$ of COPD for hip fracture was 1.23 (1.16-1.31) in women and 1.34 (1.22-1.48) in men.[40] $\mathrm{A}$ similar report from Denmark with 124,655 cases [41] also demonstrated that any osteoporotic fractures were increased with crude OR (95\% Cl) of 1.89 (1.81-1.96) with COPD. They also showed increased hip fractures in COPD in a manner dependent on the duration of hospital stay. Thus, COPD seems to be associated with an increased risk of clinical osteoporotic fractures including hip fractures.

Regan et al.[42] investigated the impact of COPD on hip fracture outcomes in a large cohort of men $(n=12,646)$ undergoing hip fracture surgery. Surprisingly, COPD was noted in $47 \%$ of their hip fracture cases, and $26 \%$ had severe COPD and showed one-year mortality of $40.2 \%$ compared with $31.0 \%$ in mild COPD and $28.8 \%$ in non-COPD subjects. Therefore, although the true incidence of hip fracture in COPD is unknown, the presence of COPD in patients with hip fractures is rather common and appeared to be associated with a poor prognosis.

\section{Bone quality in COPD}

It is generally accepted that BMD accounts for approximately $70 \%$ of bone strength.[14] Determinants of bone strength besides BMD are referred to as "bone quality," contributing to the rest (30\%) of bone strength. In some secondary osteoporosis such as those associated with diabetes mellitus and glucocorticoid excess, fracture risk depends less on BMD and more on bone quality, even though the mechanisms of deteriorated bone quality are incom- pletely understood in both conditions.[43-45] Whether or not COPD-associated fracture risk involves impaired bone quality is not only a matter of great interest but of importance in the consideration of therapeutic strategy.

Indeed, in previous studies investigating both BMD and VFx prevalence in COPD subjects, BMD was not a good predictor of fracture. Graat-Verboom et al.[8] reported that $36.5 \%$ had VFx while that only $23.6 \%$ had BMD-defined osteoporosis ( $\mathrm{T} \leq 2.5$ ). Our Japanese study of 136 COPD males [10] revealed that prevalent VFx were present in $79.4 \%$ but low BMD ( $\mathrm{T} \leq 2.5)$ only in $38.8 \%$ of the subjects. These results clearly indicate that BMD-independent mechanisms, i.e. issues with deteriorated bone quality, are involved in COPD-associated osteoporosis.

Data on bone quality in COPD is however limited: almost no data about the material properties of bone such as bone matrix protein degeneration, degree of calcification. There have been several reports on structural properties of bone. Bone biopsy is the best way to directly assess bone microarchitecture at the tissue level. There is only one report in which histomorphometric analysis was performed on the biopsied bone specimens from postmenopausal women with COPD who had not been treated with systemic glucocorticoid.[46] COPD women showed significantly decreased trabecular bone volume and connectivity density, and decreased cortical width and increased cortical porosity, compared with age-matched postmortem control samples. Connectivity density was negatively correlated with smoking (pack-years).

The trabecular bone score (TBS) is a gray-level textural metric that can be extracted from the lumbar spine DXA image, and reflects microarchitecture of trabecular bone. [47] TBS is only partially dependent on BMD, and lower TBS has been shown to be associated with higher fracture risk independent of BMD. A large retro-prospective cohort study in Manitoba investigated clinical factors associated with TBS, which demonstrated that COPD was a significant negative contributor to TBS in 29,407 women over age 50, even after adjustment for age and BMD.[48] Our preliminary study also found low TBS in COPD associated with advanced GOLD stages (Watanabe et al. unpublished results).

Taken together, these results suggest that structural deterioration affects bone strength in COPD patients. However, a recent study [49] comparing 30 COPD men with 17 controls using high-resolution peripheral quantitative comput- 
ed tomography (HR-pQCT) [50] failed to demonstrate significant difference in bone structure as well as stiffness and failure load estimated by micro finite element analysis ( $\mu \mathrm{FEA})$. Further studies will be necessary to establish clinical significance and contribution of bone quality including material properties of bone to COPD-associated osteoporosis.

\section{Bone metabolism in COPD}

Bone is subject to continuous remodeling, and the balance between resorption and formation is critical to the maintenance of bone mass and quality. Biochemical bone markers are useful to non-invasively evaluate bone metabolism.[51] A few studies have investigated bone turnover in COPD patients.

A study comparing 30 males with stable COPD with 15 age- and sex-matched ex-smoker controls found no significant differences in serum levels of amino-terminal propeptide (P1NP) or beta-isomerized C-terminal telopeptide of collagen type I ( $\beta C T X)$.[52] Negative results may be simply due to the small sample size, however, the same report demonstrated that COPD patients indeed had lower BMD, with which the two bone markers were significantly negatively correlated.

A more recent study from China [53] reported that COPD patients exhibited lower bone turnover than controls: serum levels of P1NP, $\beta C T X$, and N-Mid osteocalcin were all significantly lower in male COPD subjects than controls. In female COPD, significant differences were only observed with P1NP, suggesting that the postmenopausal status associated with high bone turnover masked otherwise suppressed bone turnover in COPD. In this study inhaled glucocorticoid (ICS) therapy had no significant impacts on any of the marker values.

Consistent with these results, dynamic histomorphometrical analysis of biopsied bone specimens from COPD patients revealed a significantly lower trabecular mineral apposition rate (MAR) compared with controls.[46] It thus seems likely that COPD is associated with diminished function of bone-forming osteoblasts resulting in low bone turnover. It should however be noted that there are multiple factors that can either enhance or suppress bone turnover to various degrees in COPD patients, including vitamin D deficiency, glucocorticoid use, immobilization, hypoxia, and so forth. Elucidation of COPD-associated changes in bone metabolism awaits further large-scale studies.
Table 1. Risk factors of osteoporosis in chronic obstructive pulmonary disease

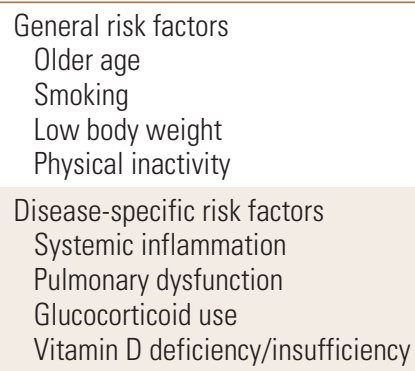

\section{Osteoporosis risk factors in COPD}

Little is known about the mechanisms that lead to osteoporosis in COPD patients. Clinical evidence has however indicated that osteoporosis and other systemic comorbidities of COPD are associated with various general and disease-specific risk factors. $[1,2,5,7,54]$ They are listed in the Table 1. In the following paragraphs we will discuss general risk factors of osteoporosis present in COPD patients followed by disease-associated factors such as systemic inflammation, pulmonary dysfunction, ICS use and vitamin $D$ deficiency/insufficiency.

\section{GENERAL RISK FACTORS FOR OSTEOPOROSIS IN COPD}

Older age and smoking are common risk factors for osteoporosis and COPD. Smoking is an established risk factor of osteoporotic fracture but has modest effect on BMD. $[55,56]$ Although our recent study suggests that smoking may inhibit bone formation (Watanabe et al. unpublished observations), exact mechanisms how smoking affect bone strength are not well known. Although to what extent smoking and the age contribute to fracture risk in COPD is unknown, it seems unlikely that osteoporosis is explained solely by aging and smoking.[38,57,58]

Body weight loss is frequently found in COPD, particularly at advanced stages, and is associated with a poor prognosis.[59] In general, body mass index (BMI) is a determinant of BMD and fracture risk in general population, and low $\mathrm{BMI}$-associated fracture risk is mostly dependent on BMD.[60] Consistently, low BMI has also been shown to predict osteoporosis and VFx among COPD patients. $[5,13]$ Weight loss and cachexia in severe COPD have been attributed to systemic inflammation with increased levels of cytokines such as tumor necrosis factor-alpha (TNF- $a$ ) and 
oxidative stress.[61] While both systemic inflammation and oxidative stress may cause metabolic abnormalities of bone directly or indirectly through sarcopenia, to what extent they contribute to the correlation between BMD and BMI in COPD patients needs further investigations.

Mechanical loading to bone is critical to the maintenance of bone mass and its structural integrity. Accordingly, reduced physical activity is an established risk factor of osteoporosis in the general population.[62,63] Physical activity scores have been shown to correlate with BMD in COPD patients. [29,64] We also found that hip BMD was negatively correlated with COPD assessment test (CAT) scores,[10] which reflect general health status and performance of COPD patients.[65] Reduced physical activity may also worsen sarcopenia and reduce sunlight exposure predisposing vitamin D deficiency/insufficiency, leading to further enhancement of bone loss.

A fracture risk assessment tool, called fracture-risk assessment tool (FRAX) has been developed and utilized worldwide to evaluate future fracture risk in general.[66] FRAX calculates 10-year probability of fractures based on clinical risk factors including age, sex, BMI or BMD, a prior fragility fracture, current smoking, history of oral glucocorticoids use, and the presence of disorders causing secondary osteoporosis including type 1 diabetes, rheumatoid arthritis but not COPD or type 2 diabetes. Of particular importance is the fact that fracture prevalence in COPD markedly exceeds that predicted by FRAX.[8,37,38] These results indicate that COPD, as type 2 diabetes, poses fracture risks not yet adopted in FRAX. Clinically, caution will be needed when assessing fracture risk with FRAX in COPD patients.

\section{DISEASE-SPECIFIC RISK FACTORS FOR OSTEOPOROSIS IN COPD}

\section{Systemic inflammation}

The pathophysiological process of COPD is characterized by infiltration of mucosa, submucosa and glandular tissue by inflammatory cells in the airway, resulting in increased mucous content, epithelial hyperplasia, which lead to airway wall thickening. Chronic inflammation and imbalance between proteases and their inhibitors cause disturbed tissue repair leading to narrowing, obliteration and destruction of terminal bronchioles.[2] Smoke-induced injury of epithelial cells stimulate release of, early cytokines such as IL-1, interleukin (IL)-8 and TNF- $a$, followed by the recruitment of immune cells including macrophages, neutrophils and dendritic cells. In addition to the basic innate immunological processes, chronic inflammatory responses involve activation of Th1, 2, 17 systems and persistent activation of resident stem cells in the lung. "Spillover" of such local inflammatory process has been hypothesized as the cause of various systemic inflammatory changes and comorbidities including osteoporosis.[2,67-69] Increased production of such cytokines, indeed, has been demonstrated, and some of them are considered as therapeutic targets of COPD.[69-71] Moreover, systemic inflammation reflected by elevated C-reactive protein (CRP) in the general population has been linked to osteoporosis and to an increased bone resorption.[72-77] Consistent with a role of inflammation in COPD-associated osteoporosis, COPD patients with lower BMD have been shown to have higher levels of CRP and inflammatory cytokines such as TNF- $a$, IL-1, and IL-6.[78,79] A simple mechanism of increased boneresorptive cytokines has however been doubted, because increased bone resorption has not been the consistent finding in COPD-associated osteoporosis. Our preliminary results suggest that systemic inflammation in COPD is associated with impaired bone microarchitecture reflected with lower TBS (unpublished observations by Watanabe et al). Precise roles of systemic inflammation in COPD-associated osteoporosis and its contribution to fracture risk remain to be determined.

\section{Pulmonary dysfunction}

Both hypercapnea and hypoxia have significant impacts on bone metabolism [80] and may predispose COPD patients to osteoporosis, especially in patients with untreated and/or severe COPD.[17]

Correlation between osteoporosis and pulmonary function has been rather extensively studied. Decreased forced expiratory volume in one second (FEV1.0) and/or advanced Global Initiative for Chronic Obstructive Lung Disease (GOLD) stages have been demonstrated to be correlated with lower BMD. $[6,8,10,27,37]$ Some $[81,82]$ but not all $[83]$ have reported correlation between BMD and FEV1.0 in the general population. In COPD patients the correlation of pulmonary function and/or GOLD stages with BMD seems to be in part mediated by BMI, whereas the correlation between BMD and with fracture prevalence was not always 
apparent.[8,10,25] Some mechanisms affecting BMD-independent fracture risk, i.e. bone quality, are present in COPD as discussed earlier. In addition, GOLD stages do not always reflect time-dependent progression of COPD. A recent study [84] has indicated that low FEV1.0 in early adulthood is important in the development of COPD and that accelerated decline in FEV1.0 is not an obligate feature of COPD. Thus, it also seems possible that COPD subjects are already susceptible to osteoporotic fractures even at early stages.

Relationship between pulmonary function and fractures in the cross-sectional studies should however be interpreted with caution, because they can mutually affect each other. VFx can cause back pain, thoracic deformities, kyphosis and height loss, all of which can result in impaired pulmonary function. A systematic review [85] on the relationship between pulmonary function and VFx in COPD has demonstrated that every single VFx is associated with a $9 \%$ decline in vital capacity (VC). Our study confirmed association of (severe) fractures with decreased VC and that of fracture number with decreased FEV1.0.[10] One longitudinal study demonstrated that decline in FEV1.0 was associated with development of osteoporosis.[86] Current evidence is, however, not enough to predict development of osteoporosis from pulmonary dysfunction and vice versa.

\section{Glucocorticoid use}

Glucocorticoid is a common and established secondary cause of osteoporosis. Glucocorticoid-induced osteoporosis (GIO) develops in a manner dependent on daily doses [87] and occurs even at small doses. GIO is generally characterized by suppressed bone formation [88] and fracture risk is partly independent of BMD.[43] Most recent studies of COPD-associated osteoporosis, however, included only a small number of subjects on systemic glucocorticoid, or demonstrated increased fracture incidence in subjects without systemic glucocorticoid use.[6,25,35] ICS or corticosteroid may be more relevant to the fracture risk in COPD subjects. A recent meta-analysis including 16 randomized controlled trials (RCTs) with 17,513 subjects and 7 observational studies with 69,000 subjects indicated that ICS was associated with a modest but significant fracture risk (OR 1.27 in the RCTs and 1.21 in observational studies). The fracture risk appeared dose-dependent. In a study of 251 COPD males, however, ICS was shown to reduce annual
BMD loss in bronchitic patients [89] most likely due to ameliorated inflammation. Therefore, overall effect of ICS seems to depend on the balance between the benefit from its local anti-inflammatory effects and the fracture risk caused by its systemic effect.

\section{Vitamin D insufficiency/deficiency}

Vitamin D insufficiency/deficiency is prevalent worldwide across all ages. Vitamin D status is evaluated with serum levels of 25-hydroxy-vitamin D [25(OH)D], which reflects its whole body store. According to the Endocrine Society clinical practice guideline,[90] vitamin $\mathrm{D}$ deficiency and insufficiency is defined as $25(\mathrm{OH}) \mathrm{D}$ levels below 20 $\mathrm{ng} / \mathrm{mL}$ and 20 to $30 \mathrm{ng} / \mathrm{mL}$, respectively. Vitamin D insufficiency/deficiency leads to reduced calcium absorption from the intestine, impaired skeletal calcification, and secondary hyperparathyroidism with high bone turnover, thereby causing bone loss and increased fracture risk. It is also associated with muscle weakness and falling, which will increase fracture risk in a BMD-independent manner. $[90,91]$

Vitamin $D$ deficiency has been shown to be highly prevalent in COPD.[92-95] Moreover, 25(OH)D levels were lower in advanced stages,[8,92-95] suggesting a link between COPD severity and vitamin $D$ deficiency.[96] The exact reason for such a link is unknown, vitamin $D$ deficiency may be caused by decreased sunlight exposure, poor diet and smoking itself [97] in COPD subjects. It has also been postulated that the vitamin $\mathrm{D}$ status may affect COPD development and exacerbations.[98] Although interventions with vitamin $\mathrm{D}$ supplementation have not been able to provide sufficient evidence for its general efficacy, a subanalysis of subjects with $25(\mathrm{OH}) \mathrm{D}$ levels below $20 \mathrm{ng} / \mathrm{mL}$ demonstrated that vitamin $\mathrm{D}$ was indeed beneficial to those with vitamin D deficiency.[99] Role of vitamin D in the long-term prognosis of COPD patients remains to be determined.

A couple of studies have demonstrated that the vitamin $D$ status is indeed correlated with BMD in COPD subjects. $[92,93]$ And one longitudinal study demonstrated that in 100 stable COPD patients baseline vitamin D deficiency increased the risk for osteoporosis development by 7.5 fold during a 3-year follow-up period.[86] It should be emphasized that the increase in osteoporosis during the followup in this study was in most cases due to newly diagnosed 
VFx. These results support a role for vitamin D insufficiency/deficiency in COPD-associated osteoporosis, but its contribution to the fracture risk in COPD patients should be more precisely evaluated in a larger prospective study in the future.

\section{CONCLUSION}

There is ample evidence that osteoporosis and osteoporotic fractures are very common in COPD patients. Although the mechanisms by which COPD leads to osteoporosis are yet unclear, patients with COPD have a host of general and disease-specific risk factors for osteoporosis. One important issue with COPD-associated osteoporosis is its extreme under-recognition by physicians resulting in extreme under-treatment. It is important for pulmonologists, as well as general physicians, to be aware of the high prevalence of osteoporosis in COPD patients and to evaluate them for fracture risks.[100] Routine screening for osteoporosis will enable physicians to diagnose COPD patients with comorbid osteoporosis at an early stage and to give them appropriate treatment to prevent fracture, which may lead to improved QOL as well as better long-term prognosis in these patients.

\section{REFERENCES}

1. Sarkar M, Bhardwaj R, Madabhavi I, et al. Osteoporosis in chronic obstructive pulmonary disease. Clin Med Insights Circ Respir Pulm Med 2015;9:5-21.

2. Decramer M, Janssens W, Miravitlles M. Chronic obstructive pulmonary disease. Lancet 2012;379:1341-51.

3. Burgel PR, Escamilla R, Perez T, et al. Impact of comorbidities on COPD-specific health-related quality of life. Respir Med 2013;107:233-41.

4. Frei A, Muggensturm P, Putcha N, et al. Five comorbidities reflected the health status in patients with chronic obstructive pulmonary disease: the newly developed COMCOLD index. J Clin Epidemiol 2014;67:904-11.

5. Graat-Verboom L, Wouters EF, Smeenk FW, et al. Current status of research on osteoporosis in COPD: a systematic review. Eur Respir J 2009;34:209-18.

6. Kjensli A, Falch JA, Ryg M, et al. High prevalence of vertebral deformities in COPD patients: relationship to disease severity. Eur Respir J 2009;33:1018-24.
7. Lehouck A, Boonen S, Decramer M, et al. COPD, bone metabolism, and osteoporosis. Chest 2011;139:648-57.

8. Graat-Verboom L, van den Borne BE, Smeenk FW, et al. Osteoporosis in COPD outpatients based on bone mineral density and vertebral fractures. J Bone Miner Res 2011;26: 561-8.

9. Regan E, Jaramillo J. It's the fracture that matters -bone disease in COPD patients. Copd 2012;9:319-21.

10. Watanabe R, Tanaka T, Aita K, et al. Osteoporosis is highly prevalent in Japanese males with chronic obstructive pulmonary disease and is associated with deteriorated pulmonary function. J Bone Miner Metab 2015;33:392-400.

11. Ryan CS, Petkov Vl, Adler RA. Osteoporosis in men: the value of laboratory testing. Osteoporos Int 2011;22:1845-53.

12. Carter JD, Patel S, Sultan FL, et al. The recognition and treatment of vertebral fractures in males with chronic obstructive pulmonary disease. Respir Med 2008;102:1165-72.

13. Majumdar SR, Villa-Roel C, Lyons KJ, et al. Prevalence and predictors of vertebral fracture in patients with chronic obstructive pulmonary disease. Respir Med 2010;104:260-6.

14. NIH Consensus Development Panel on Osteoporosis Prevention, Diagnosis, and Therapy. Osteoporosis prevention, diagnosis, and therapy. JAMA 2001;285:785-95.

15. Aris RM, Neuringer IP, Weiner MA, et al. Severe osteoporosis before and after lung transplantation. Chest 1996;109: 1176-83.

16. Incalzi RA, Caradonna P, Ranieri P, et al. Correlates of osteoporosis in chronic obstructive pulmonary disease. Respir Med 2000;94:1079-84.

17. Dimai HP, Domej W, Leb G, et al. Bone loss in patients with untreated chronic obstructive pulmonary disease is mediated by an increase in bone resorption associated with hypercapnia. J Bone Miner Res 2001;16:2132-41.

18. Dubois EF, Röder E, Dekhuijzen PN, et al. Dual energy Xray absorptiometry outcomes in male COPD patients after treatment with different glucocorticoid regimens. Chest 2002;121:1456-63.

19. Tschopp O, Boehler A, Speich R, et al. Osteoporosis before lung transplantation: association with low body mass index, but not with underlying disease. Am J Transplant 2002; 2:167-72.

20. Katsura H, Kida K. A comparison of bone mineral density in elderly female patients with COPD and bronchial asthma. Chest 2002;122:1949-55.

21. Karadag F, Cildag O, Yurekli Y, et al. Should COPD patients 
be routinely evaluated for bone mineral density? J Bone Miner Metab 2003;21:242-6.

22. Bolton $C E$, lonescu AA, Shiels KM, et al. Associated loss of fat-free mass and bone mineral density in chronic obstructive pulmonary disease. Am J Respir Crit Care Med 2004; 170:1286-93.

23. Førli L, Mellbye OJ, Halse J, et al. Cytokines, bone turnover markers and weight change in candidates for lung transplantation. Pulm Pharmacol Ther 2008;21:188-95.

24. Mineo TC, Ambrogi V, Mineo D, et al. Bone mineral density improvement after lung volume reduction surgery for severe emphysema. Chest 2005;127:1960-6.

25. Jørgensen NR, Schwarz P, Holme I, et al. The prevalence of osteoporosis in patients with chronic obstructive pulmonary disease: a cross sectional study. Respir Med 2007;101: 177-85.

26. Sabit R, Bolton CE, Edwards PH, et al. Arterial stiffness and osteoporosis in chronic obstructive pulmonary disease. Am J Respir Crit Care Med 2007;175:1259-65.

27. Vrieze A, de Greef MH, Wijkstra PJ, et al. Low bone mineral density in COPD patients related to worse lung function, low weight and decreased fat-free mass. Osteoporos Int 2007;18:1197-202.

28. Ferguson GT, Calverley PM, Anderson JA, et al. Prevalence and progression of osteoporosis in patients with COPD: results from the TOwards a Revolution in COPD Health study. Chest 2009;136:1456-65.

29. Silva DR, Coelho AC, Dumke A, et al. Osteoporosis prevalence and associated factors in patients with COPD: a crosssectional study. Respir Care 2011;56:961-8.

30. Schnell K, Weiss CO, Lee T, et al. The prevalence of clinically-relevant comorbid conditions in patients with physician-diagnosed COPD: a cross-sectional study using data from NHANES 1999-2008. BMC Pulm Med 2012;12:26.

31. Hattiholi J, Gaude GS. Prevalence and correlates of osteoporosis in chronic obstructive pulmonary disease patients in India. Lung India 2014;31:221-7.

32. Dam TT, Harrison S, Fink HA, et al. Bone mineral density and fractures in older men with chronic obstructive pulmonary disease or asthma. Osteoporos Int 2010;21:1341-9.

33. Chen SJ, Liao WC, Huang KH, et al. Chronic obstructive pulmonary disease and allied conditions is a strong independent risk factor for osteoporosis and pathologic fractures: a population-based cohort study. QJM 2015;108: 633-40.
34. McEvoy CE, Ensrud KE, Bender E, et al. Association between corticosteroid use and vertebral fractures in older men with chronic obstructive pulmonary disease. Am J Respir Crit Care Med 1998;157:704-9.

35. Papaioannou A, Parkinson W, Ferko N, et al. Prevalence of vertebral fractures among patients with chronic obstructive pulmonary disease in Canada. Osteoporos Int 2003; 14:913-7.

36. Nuti R, Siviero $P$, Maggi S, et al. Vertebral fractures in patients with chronic obstructive pulmonary disease: the EOLO Study. Osteoporos Int 2009;20:989-98.

37. Ogura-Tomomatsu H, Asano K, Tomomatsu K, et al. Predictors of osteoporosis and vertebral fractures in patients presenting with moderate-to-severe chronic obstructive lung disease. Copd 2012;9:332-7.

38. Dennison EM, Compston JE, Flahive J, et al. Effect of comorbidities on fracture risk: findings from the Global Longitudinal Study of Osteoporosis in Women (GLOW). Bone 2012;50:1288-93.

39. de Vries F, van Staa TP, Bracke MS, et al. Severity of obstructive airway disease and risk of osteoporotic fracture. Eur Respir J 2005;25:879-84.

40. Hippisley-Cox J, Coupland C. Derivation and validation of updated QFracture algorithm to predict risk of osteoporotic fracture in primary care in the United Kingdom: prospective open cohort study. BMJ 2012;344:e3427.

41. Vestergaard $P$, Rejnmark L, Mosekilde L. Fracture risk in patients with chronic lung diseases treated with bronchodilator drugs and inhaled and oral corticosteroids. Chest 2007;132:1599-607.

42. Regan EA, Radcliff TA, Henderson WG, et al. Improving hip fractures outcomes for COPD patients. Copd 2013;10:11-9.

43. Van Staa TP, Laan RF, Barton IP, et al. Bone density threshold and other predictors of vertebral fracture in patients receiving oral glucocorticoid therapy. Arthritis Rheum 2003; 48:3224-9.

44. Vestergaard P. Discrepancies in bone mineral density and fracture risk in patients with type 1 and type 2 diabetes--a meta-analysis. Osteoporos Int 2007;18:427-44.

45. Unnanuntana A, Rebolledo BJ, Khair MM, et al. Diseases affecting bone quality: beyond osteoporosis. Clin Orthop Relat Res 2011;469:2194-206.

46. Kulak CA, Borba VC, Jorgetti V, et al. Skeletal microstructural abnormalities in postmenopausal women with chronic obstructive pulmonary disease. J Bone Miner Res 2010; 
25:1931-40.

47. Silva BC, Leslie WD, Resch $\mathrm{H}$, et al. Trabecular bone score: a noninvasive analytical method based upon the DXA image. J Bone Miner Res 2014;29:518-30.

48. Leslie WD, Krieg MA, Hans D. Clinical factors associated with trabecular bone score. J Clin Densitom 2013;16:374-9.

49. Romme EA, Rutten EP, Geusens P, et al. Bone stiffness and failure load are related with clinical parameters in men with chronic obstructive pulmonary disease. J Bone Miner Res 2013;28:2186-93.

50. Link TM. Osteoporosis imaging: state of the art and advanced imaging. Radiology 2012;263:3-17.

51. Naylor K, Eastell R. Bone turnover markers: use in osteoporosis. Nat Rev Rheumatol 2012;8:379-89.

52. Duckers JM, Evans BA, Fraser WD, et al. Low bone mineral density in men with chronic obstructive pulmonary disease. Respir Res 2011;12:101.

53. Xiaomei W, Hang X, Lingling $L$, et al. Bone metabolism status and associated risk factors in elderly patients with chronic obstructive pulmonary disease (COPD). Cell Biochem Biophys 2014;70:129-34.

54. Romme EA, Smeenk FW, Rutten EP, et al. Osteoporosis in chronic obstructive pulmonary disease. Expert Rev Respir Med 2013;7:397-410.

55. Ward KD, Klesges RC. A meta-analysis of the effects of cigarette smoking on bone mineral density. Calcif Tissue Int 2001;68:259-70.

56. Kanis JA, Johnell O, Oden A, et al. Smoking and fracture risk: a meta-analysis. Osteoporos Int 2005;16:155-62.

57. Boyer L, Chouaïd C, Bastuji-Garin S, et al. Aging-related systemic manifestations in COPD patients and cigarette smokers. PLoS One 2015;10:e0121539.

58. Jaramillo JD, Wilson C, Stinson DS, et al. Reduced Bone Density and Vertebral Fractures in Smokers. Men and COPD Patients at Increased Risk. Ann Am Thorac Soc 2015;12: 648-56.

59. Vestbo J, Prescott E, Almdal T, et al. Body mass, fat-free body mass, and prognosis in patients with chronic obstructive pulmonary disease from a random population sample: findings from the Copenhagen City Heart Study. Am J Respir Crit Care Med 2006;173:79-83.

60. De Laet C, Kanis JA, Odén A, et al. Body mass index as a predictor of fracture risk: a meta-analysis. Osteoporos Int 2005;16:1330-8.

61. Remels AH, Gosker HR, Langen RC, et al. The mechanisms of cachexia underlying muscle dysfunction in COPD. J Appl Physiol (1985) 2013;114:1253-62.

62. Nguyen TV, Center JR, Eisman JA. Osteoporosis in elderly men and women: effects of dietary calcium, physical activity, and body mass index. J Bone Miner Res 2000;15: 322-31.

63. Johansson J, Nordström A, Nordström P. Objectively measured physical activity is associated with parameters of bone in 70-year-old men and women. Bone 2015;81:72-9.

64. Miller J, Edwards LD, Agustí A, et al. Comorbidity, systemic inflammation and outcomes in the ECLIPSE cohort. Respir Med 2013;107:1376-84.

65. Tsuda T, Suematsu R, Kamohara K, et al. Development of the Japanese version of the COPD Assessment Test. Respir Investig 2012;50:34-9.

66. Kanis JA, Oden A, Johansson H, et al. FRAX and its applications to clinical practice. Bone 2009;44:734-43.

67. Barnes PJ. Mediators of chronic obstructive pulmonary disease. Pharmacol Rev 2004;56:515-48.

68. Sinden NJ, Stockley RA. Systemic inflammation and comorbidity in COPD: a result of 'overspill' of inflammatory mediators from the lungs? Review of the evidence. Thorax 2010;65:930-6.

69. Hoepers AT, Menezes MM, Fröde TS. Systematic review of anaemia and inflammatory markers in chronic obstructive pulmonary disease. Clin Exp Pharmacol Physiol 2015;42: 231-9.

70. Eagan TM, Ueland T, Wagner PD, et al. Systemic inflammatory markers in COPD: results from the Bergen COPD Cohort Study. Eur Respir J 2010;35:540-8.

71. Bade G, Khan MA, Srivastava AK, et al. Serum cytokine profiling and enrichment analysis reveal the involvement of immunological and inflammatory pathways in stable patients with chronic obstructive pulmonary disease. Int J Chron Obstruct Pulmon Dis 2014;9:759-73.

72. Tomiyama H, Okazaki R, Koji Y, et al. Elevated C-reactive protein: a common marker for atherosclerotic cardiovascular risk and subclinical stages of pulmonary dysfunction and osteopenia in a healthy population. Atherosclerosis 2005;178:187-92.

73. Koh JM, Khang YH, Jung $\mathrm{CH}$, et al. Higher circulating hsCRP levels are associated with lower bone mineral density in healthy pre- and postmenopausal women: evidence for a link between systemic inflammation and osteoporosis. Osteoporos Int 2005;16:1263-71. 
74. Kim BJ, Yu YM, Kim EN, et al. Relationship between serum hsCRP concentration and biochemical bone turnover markers in healthy pre- and postmenopausal women. Clin Endocrinol (Oxf) 2007;67:152-8.

75. de Pablo P, Cooper MS, Buckley CD. Association between bone mineral density and C-reactive protein in a large population-based sample. Arthritis Rheum 2012;64:2624-31.

76. Ahmadi-Abhari S, Luben RN, Wareham NJ, et al. C-reactive protein and fracture risk: European prospective investigation into Cancer Norfolk Study. Bone 2013;56:67-72.

77. Berglundh S, Malmgren L, Luthman $\mathrm{H}$, et al. C-reactive protein, bone loss, fracture, and mortality in elderly women: a longitudinal study in the OPRA cohort. Osteoporos Int 2015;26:727-35.

78. Bai P, Sun Y, Jin J, et al. Disturbance of the OPG/RANK/RANKL pathway and systemic inflammation in COPD patients with emphysema and osteoporosis. Respir Res 2011;12:157.

79. Liang B, Feng Y. The association of low bone mineral density with systemic inflammation in clinically stable COPD. Endocrine 2012;42:190-5.

80. Arnett TR. Acidosis, hypoxia and bone. Arch Biochem Biophys 2010;503:103-9.

81. Choi JW, Pai SH. Association between respiratory function and osteoporosis in pre- and postmenopausal women. Maturitas 2004;48:253-8.

82. Jeon YK, Shin MJ, Kim WJ, et al. The relationship between pulmonary function and bone mineral density in healthy nonsmoking women: the Korean National Health and Nutrition Examination Survey (KNHANES) 2010. Osteoporos Int 2014;25:1571-6.

83. Dennison EM, Dhanwal DK, Shaheen SO, et al. Is lung function associated with bone mineral density? Results from the Hertfordshire Cohort Study. Arch Osteoporos 2013;8: 115.

84. Lange P, Celli B, Agustí A, et al. Lung-Function Trajectories Leading to Chronic Obstructive Pulmonary Disease. N Engl J Med 2015;373:111-22.

85. Harrison RA, Siminoski K, Vethanayagam D, et al. Osteoporosis-related kyphosis and impairments in pulmonary function: a systematic review. J Bone Miner Res 2007;22: 447-57.

86. Graat-Verboom L, Smeenk FW, van den Borne BE, et al. Progression of osteoporosis in patients with COPD: a 3-year follow up study. Respir Med 2012;106:861-70.

87. van Staa TP, Leufkens HG, Abenhaim L, et al. Oral corticosteroids and fracture risk: relationship to daily and cumu- lative doses. Rheumatology (Oxford) 2000;39:1383-9.

88. Ton FN, Gunawardene SC, Lee H, et al. Effects of low-dose prednisone on bone metabolism. J Bone Miner Res 2005; 20:464-70.

89. Mathioudakis AG, Amanetopoulou SG, Gialmanidis IP, et al. Impact of long-term treatment with low-dose inhaled corticosteroids on the bone mineral density of chronic obstructive pulmonary disease patients: aggravating or beneficial? Respirology 2013;18:147-53.

90. Holick MF, Binkley NC, Bischoff-Ferrari HA, et al. Evaluation, treatment, and prevention of vitamin D deficiency: an Endocrine Society clinical practice guideline. J Clin Endocrinol Metab 2011;96:1911-30.

91. Ebeling PR. Vitamin D and bone health: Epidemiologic studies. Bonekey Rep 2014;3:511.

92. Førli L, Halse J, Haug E, et al. Vitamin D deficiency, bone mineral density and weight in patients with advanced pulmonary disease. J Intern Med 2004;256:56-62.

93. Romme EA, Rutten EP, Smeenk FW, et al. Vitamin D status is associated with bone mineral density and functional exercise capacity in patients with chronic obstructive pulmonary disease. Ann Med 2013;45:91-6.

94. Janssens W, Bouillon R, Claes B, et al. Vitamin D deficiency is highly prevalent in COPD and correlates with variants in the vitamin D-binding gene. Thorax 2010;65:215-20.

95. Persson LJ, Aanerud M, Hiemstra PS, et al. Chronic obstructive pulmonary disease is associated with low levels of vitamin D. PLoS One 2012;7:e38934.

96. Zhu B, Zhu B, Xiao C, et al. Vitamin D deficiency is associated with the severity of COPD: a systematic review and meta-analysis. Int J Chron Obstruct Pulmon Dis 2015;10: 1907-16.

97. Brot $\mathrm{C}$, Jorgensen NR, Sorensen $\mathrm{OH}$. The influence of smoking on vitamin D status and calcium metabolism. Eur J Clin Nutr 1999;53:920-6.

98. Janssens W, Decramer M, Mathieu C, et al. Vitamin D and chronic obstructive pulmonary disease: hype or reality? Lancet Respir Med 2013;1:804-12.

99. Martineau AR, James WY, Hooper RL, et al. Vitamin D3 supplementation in patients with chronic obstructive pulmonary disease (ViDiCO): a multicentre, double-blind, randomised controlled trial. Lancet Respir Med 2015;3:120-30.

100. Inoue D, Watanabe R, Okazaki R. COPD and osteoporosis: links, risks, and treatment challenges. Int J Chron Obstruct Pulmon Dis 2016;11:637-48. 